\title{
Photodegradation of Fluoxetine Applying Different Photolytic Reactors: Evaluation of the Process Efficiency and Mechanism
}

\author{
Ailton J. Moreira, ${ }^{\oplus * a}$ Aline C. Borges, ${ }^{a}$ Bianca B. de Sousa, ${ }^{\oplus a}$ \\ Vagner R. de Mendonça, ${ }^{b}$ Carolina D. Freschi ${ }^{a}$ and Gian P. G. Freschi ${ }^{a}$ \\ ${ }^{a}$ Laboratório de Fotólise, Fotocatálise e Especiação Química (LAFFEQ), \\ Instituto de Ciência e Tecnologia, Universidade Federal de Alfenas (UNIFAL-MG), \\ 37715-400 Poços de Caldas-MG, Brazil \\ ${ }^{b}$ Instituto Federal de Ciência e Tecnologia de São Paulo (IFSP), Campus Itapetininga, \\ 18202-000 Itapetininga-SP, Brazil
}

\begin{abstract}
Photolytic degradation of fluoxetine (FLX), a medicine commonly known as Prozac ${ }^{\circledR}$, was evaluated by using different photochemical processes. The ultraviolet/microwave (UV/MW) process showed higher efficiency in all the aspects evaluated in this study. The energy consumption was equivalent to $1.94 \times 10^{-4} \mathrm{~kW} \mathrm{~h} \mathrm{mg}^{-1} \mathrm{~L}$ (UV/MW), while in the UV process the value was $1.20 \times 10^{-2} \mathrm{~kW} \mathrm{~h} \mathrm{mg}^{-1} \mathrm{~L}$. The degradation kinetics were applied to the FLX, with rate constant $(\mathrm{k})=0.15 \pm 0.01 \mathrm{~min}^{-1}$ and linear correlation coefficient $\left(\mathrm{R}^{2}\right)=0.980$ for $\mathrm{UV}$, and $\mathrm{k}=6.15 \pm 0.08 \mathrm{~min}^{-1}$ and $\mathrm{R}^{2}=0.998$ for UV/MW. The FLX degradation of $99.16 \%$ (UV/MW $5 \mathrm{~min}$ ) and $98.90 \%$ (UV $120 \mathrm{~min}$ ) were observed, evidencing higher efficiency for the first process. The monitoring of transformation products (TPs) through chromatographic analysis enabled the identification of $9 \mathrm{TPs}$, proving that for the UV/MW process, the hydroxylated structures are verified in high quantity.
\end{abstract}

Keywords: fluoxetine, photochemical reactor, transformation products, photolysis, kinetics

\section{Introduction}

The environmental contamination by pharmaceuticals has attracted the attention of the scientific community and environmental protection agencies since many pharmaceuticals have been found in the most diverse ecosystems. ${ }^{1,2}$ Studies identified the presence of 30 types of pharmaceuticals in an aquatic environment affected by the disposal of effluents from a municipal treatment plant, besides verifying the presence of some of these pharmaceuticals in benthic communities. ${ }^{1}$ Other studies conducted identified the presence of 43 pharmaceuticals in 50 effluent treatment plants. ${ }^{2}$ The concern about the presence of these pharmaceuticals in ecosystems is necessary since fluoxetine (FLX, an antidepressant widely used in the world) has the capacity to interfere in the life cycle of aquatic species, even in low concentrations $\left(10 \mu \mathrm{g} \mathrm{L}^{-1}\right){ }^{3}$

Due to the observation of the presence of these compounds in different ecosystems and especially their

*e-mail: aijomoquim@gmail.com persistence in the environment (difficult degradation), many studies have been carried out to find new alternatives for the treatment of effluents of persistent compounds. ${ }^{4-7}$ Many of these new processes have been applied in the degradation of FLX. ${ }^{8-11}$ It is important to note that the efficiency of degradation of chemical compounds through different processes needs to be verified through some important parameters, such as energy consumption, reagent costs, process time, TPs and, in particular, chemical kinetics. ${ }^{12,13}$

Hence, the studies attribute a kinetic behavior of pseudofirst-order for the degradation of FLX, ${ }^{14-16}$ which may can occur through direct photolysis, indirect photolysis, and hydrolysis. ${ }^{17}$ Hydrolysis is not very acceptable since, after a long period of permanence in a degradation system, the hydrolytic degradation of FLX has not been observed. ${ }^{17,18}$ Therefore, it shows that the compound is stable in aqueous solution in the absence of light. ${ }^{19}$ Many factors influence the degradation of FLX, with by example, the radical oxidation $\left({ }^{\bullet} \mathrm{OH}\right)$ and direct photolysis (UV)..$^{15,19,20}$

The degradation kinetic of a given compound, especially those that of adjustment to pseudo-second-order kinetics present more complex degradation mechanisms. ${ }^{6}$ 
Moreover, the understanding of these mechanisms occurs with the monitoring of their transformation products (TPs), thus, allowing to correlate the behavior of a transformation product to its original pharmaceutical compound. ${ }^{10}$ FLX is a halogenated compound and studies show that through human metabolism, $o$-dealkylation of FLX promotes the formation of the trihalogenated compound 4-(trifluoromethyl)phenol (TFMP). ${ }^{21}$ The TPs resulting from the degradation of FLX have been identified and quantified through various analytical techniques, ${ }^{10,15,22-24}$ on account of this it can be considered an essential step to define the true kinetic behavior of FLX degradation.

Some of the TPs of FLX may undergo dehalogenation through photolytic/photocatalytic degradation and monitoring the additions of fluoride in the solution is indirectly related to the degradation of FLX. ${ }^{15,16}$ The pseudo-first-order kinetics for the formation of fluoride after degradation of FLX was reported in the literature, ${ }^{6,15}$ showing that the values of the constants are influenced by medium conditions ( $\mathrm{pH}$ and process time).

Therefore, FLX degradation can be better understood by qualitative and quantitative analytical monitoring of the process and products. ${ }^{6,10}$ The TPs formed can influence the degradation of the original compound and their monitoring allows for advances in the kinetic understanding of FLX degradation. ${ }^{19,23}$ It is also worth noting that the definition of the mechanisms of degradation and the influence of different energies applied to advanced oxidative processes are of scientific interest.

The data in the literature ${ }^{10,25,26}$ show that different photochemical systems have been studied in the degradation of emerging pollutants. However, those that allow a higher formation of strong oxidants, especially hydroxyl radicals, have attracted more attention. In this case, the ultraviolet/ microwave (UV/MW) reactor, consisting of a microwave discharge electrodeless mercury lamp (Hg-MDEL), when applied (at a laboratory scale), have high degradation rate values. ${ }^{27,28}$

The Hg-MDEL has the capacity to emit clean spectra with greater intensity and different bands of wavelength, the latter being dependent on the composition of the material..$^{29}$ It is important to note that these systems have a history of use in organic synthesis. ${ }^{30-32}$ However, in the last decades, their application has been investigated in advanced oxidative processes, allowing degradation of atrazine in periods of $0.083 \mathrm{~min}$ and $39 \%$ removal of the dye $\mathrm{AO} 7 \mathrm{in}$ periods of $120 \mathrm{~min}^{33,34}$

Considering the number of pharmaceuticals reported in different ecosystems, the impact that they cause and the high persistence in the environment, it is important to evaluate the applicability of new photochemical systems in environmental remediation. Especially the Hg-MDEL, which have a positive history of efficiency in degradation processes. Thus, it allows us to consider the importance of evaluating its application in the degradation of FLX. Moreover, based on our work, the UV/MW reactor was employed for the first time to FLX degradation.

In general, the objectives of this work are to evaluate the process of FLX degradation, (studying the effect of initial concentration, $\mathrm{pH}$, time, reactor type), calculate the amount of energy consumed in the degradation process of the FLX, in each reactor, calculate the values of kinetic constant of degradation and, finally, monitoring the transformation products generated after the degradation of FLX.

\section{Experimental}

\section{Materials and methods}

The UV-Vis Cary 60 spectrophotometer (Agilent, Santa Clara, CA, USA), was used for preliminary analysis of the FLX through molecular absorption measurements.

The photolytic experiments in the UV region were performed in a $50 \mathrm{~mL}$ glass beaker and were placed in a wooden reactor. Its internal dimensions were $45 \mathrm{~cm}$ (length) $\times 20 \mathrm{~cm}$ (width) $\times 28 \mathrm{~cm}$ (height) and $23 \mathrm{~cm}$ height between the lamp and the solution to be irradiated. In addition, the UV reactor also consisted of 4 low-pressure mercury Philips lamps TUV 15 W/G15T8 (Amsterdam, Netherlands), long life, UV-C $\left(\lambda_{\max }=254 \mathrm{~nm}\right),{ }^{1}$ cooler axial AC FAN Model FZY8038 MBL (Shanghai, China) and a copper serpentine coil coupled to an ultrathermostatic bath SL 152/18, SOLAB $2000 \mathrm{~W} / 220 \mathrm{~V}$ (Piracibaca, Brazil) with a water pump and temperature control of $20^{\circ} \mathrm{C}$ (Figure 1a). Photolytic energy studies using microwave (MW) and associated ultraviolet (UV) were carried out on the MARS 6, $220 \mathrm{~V}, 60 \mathrm{~Hz}$ CEM equipment (Matthews, USA) with a microwave frequency of $2,450 \mathrm{MHz}$ and power up to $1,800 \mathrm{~W}$, as well as a UV/MW reactor (Hg-MDEL, UMEX GmbH Hg: 254 nm, Dresden, Germany) with a $10 \mathrm{~mL}$ quartz sample compartment supported in a $250 \mathrm{~mL}$ glass beaker. Photolytic studies using microwave energy were performed on the same equipment in the absence of the UV/MW reactor (Figure 1b). Note that the temperature variation is not significant for the applied time period (up to $2 \mathrm{~min}$ ), since the microwave is absorbed to drive Hg-MDEL and does not reach the FLX solution.

To determine the radiation spectra emitted by the photoreactor, a spectroradiometer SPR-4002 (Luzchem, Ottawa, Canada) was used, with a spectral reading range of 230 to $900 \mathrm{~nm}$, covering the UVA, UVB, UVC and visible 
(a)
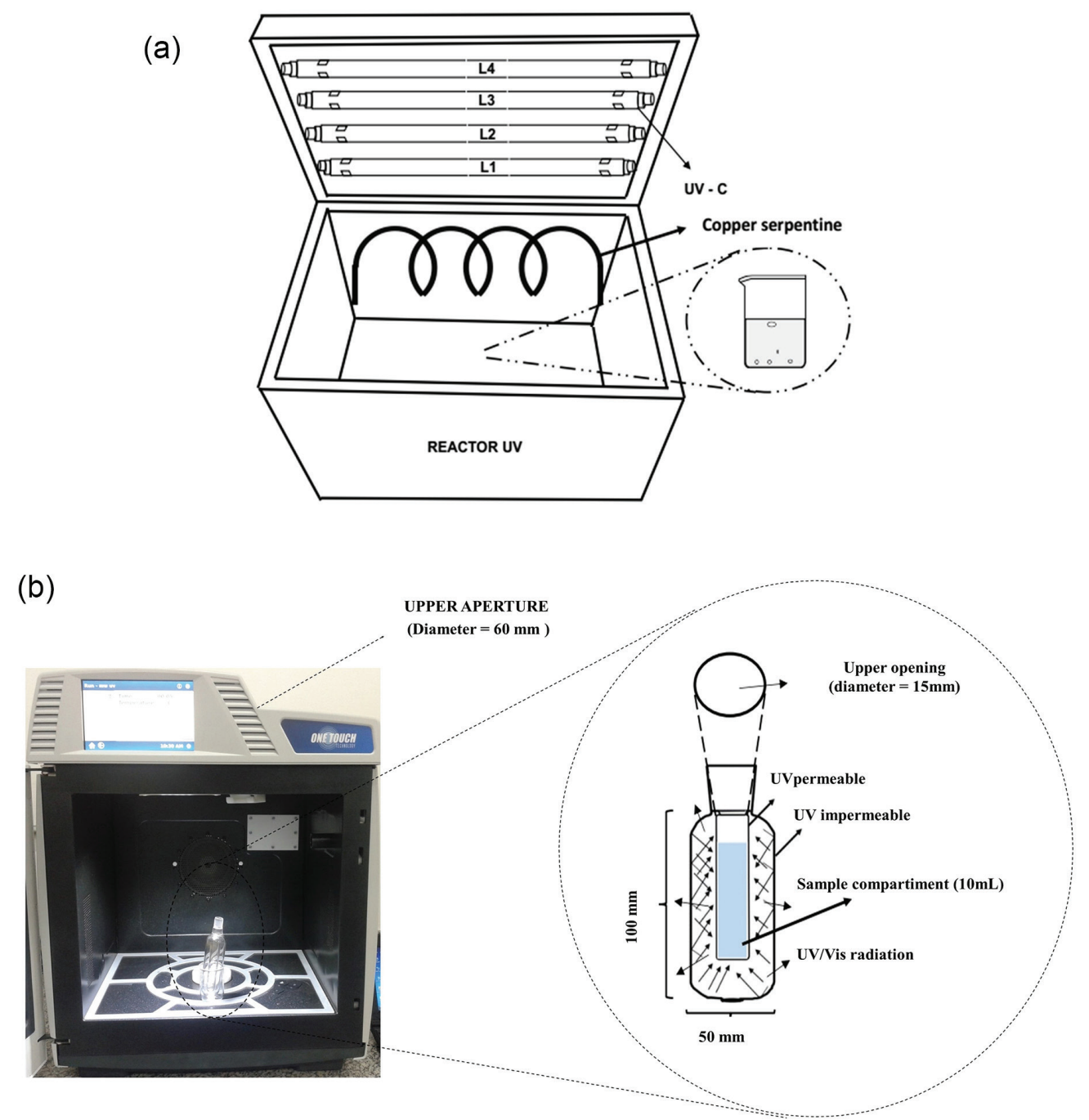

Figure 1. Illustrative picture of the (a) UV and (b) UV/MW photoreactors applied in the FLX photodegradation.

regions. The radiation spectra were quantified through the intensity of $\mathrm{mW} \mathrm{m} \mathrm{m}^{-2}$.

The chromatographic analyses were performed on a high performance liquid chromatography (HPLC) Agilent 1220 Infinity LC (Santa Clara, USA) equipped with an automatic sampler, an oven temperature control column, a UV-Vis detector system $(225 \mathrm{~nm})$ and a chromatographic column Zorbax Eclipse Plus C18 (Santa Clara, USA), $4.6 \times 250 \mathrm{~mm}, 5 \mu \mathrm{m}$. The processing of chromatographic data was administered by the Agilent OpenLAB Chromatography Data System Software (CDS) EZChrom (Santa Clara, USA). After irradiation, the solutions were monitored by UV-Vis HPLC and the FLX removal rate was determined. The chromatographic conditions were: elution gradient $\left(\mathrm{v} \mathrm{v}^{-1}\right): 0$ min, 50\% (ACN)/50\% $\mathrm{PO}_{4}{ }^{3-}$ buffer ( $\mathrm{pH}=3) ; 0$ to $1 \mathrm{~min}, 45 \%(\mathrm{ACN}) / 55 \% \mathrm{PO}_{4}{ }^{3-}$ buffer $(\mathrm{pH}=3) ; 1$ to $4 \mathrm{~min}, 75 \%(\mathrm{ACN}) / 25 \% \mathrm{PO}_{4}^{3-}$ buffer $(\mathrm{pH}=3) ; 4$ to $5 \mathrm{~min}, 90 \%(\mathrm{ACN}) / 10 \% \mathrm{PO}_{4}^{3-}$ buffer
$(\mathrm{pH}=3) ; 5$ to $7 \mathrm{~min}, 100 \% \mathrm{ACN}$, detecting at $225 \mathrm{~nm}$, a mobile phase flow rate of $1 \mathrm{~mL} \mathrm{~min}{ }^{-1}$ and a temperature control of $35^{\circ} \mathrm{C}$. The quantification parameters are: limit of quantification $(\mathrm{LOQ})=1.22 \mathrm{mg} \mathrm{L}^{-1}$ and linear correlation coefficient $\left(\mathrm{R}^{2}\right)=0.9979$ for FLX; and LOQ $=0.516 \mathrm{mg} \mathrm{L}^{-1}$ and $\mathrm{R}^{2}=0.9996$ for TFMP, operating in the concentration range of $0.05-20 \mathrm{mg} \mathrm{L}^{-1}$ and $95 \%$ confidence level.

TPs generated from FLX degradation by UV (irradiated for 3 and $60 \mathrm{~min}$ ) and by UV/MW (irradiated for 0.083 and $2.0 \mathrm{~min}$ ) were identified by Agilent 6530 Accurate-Mass Quadrupole Time-of-Flight (Q-TOF) LC-mass spectrometry (MS) system. The chromatographic conditions used for the separation are: mobile phase consisting of aqueous solution of formic acid $0.1 \%\left(\mathrm{v} \mathrm{v}^{-1}\right)(\mathrm{A})$ and acetonitrile (B) with elution gradient: $0 \mathrm{~min}(90 \% \mathrm{~A} / 10 \% \mathrm{~B})$ at $10 \mathrm{~min}(20 \%$

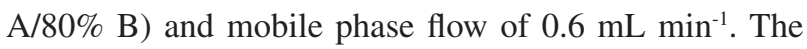
time-of-flight mass spectra were obtained in positive electrospray $($ ESI $(+)$ TIC Scan Frag $=175$ V) mode in the 
range $m / z, 100-1,000$ at the following optimized operating conditions: nebulizer, $45.0 \mathrm{psig}$; dry gas, $10.0 \mathrm{~L} \mathrm{~min}^{-1}$; dry heater, $325{ }^{\circ} \mathrm{C}$; and capillary at $3,500 \mathrm{~V}$. Data were processed using Agilent Mass Hunter Qualitative Analysis software (version B.08.00; Agilent, Santa Clara, CA, USA).

\section{Reagents and analytical solutions}

The $1000 \mathrm{mg} \mathrm{L}^{-1}$ FLX standard solution (98.5\%, purchased from Santa Cecilia pharmacy, MG, Brazil) and 4-(trifluoromethyl)phenol (TFMP) 97\% (Sigma-Aldrich, St. Louis, MO, USA) were prepared. A phosphate buffer, $\mathrm{pH}=3.0\left(10.0 \mathrm{mmol} \mathrm{L}-1 \mathrm{KH}_{2} \mathrm{PO}_{4}\right)$, was prepared by dissolving the respective salts (Sigma-Aldrich, St. Louis, MO, USA), adjusting the $\mathrm{pH}$ with $85 \%$ phosphoric acid (Neon, Suzano, Brazil).

Acetonitrile and methanol, HPLC grade (J.T. Baker, USA), were used in the preparation of solutions and processes linked to the chromatographic analysis. The respective pharmaceuticals standard solutions were prepared in ultrapure water and not in environmental matrices.

Coumarin (COU) (98\%, Sigma-Aldrich, St. Louis, MO, USA) was used for identification of hydroxyl radicals, and dimethyl sulfoxide (DMSO) (99.9\%, Sigma-Aldrich, St. Louis, MO, USA) as a hydroxyl radical scavenger. In this step, the quantification of $\mathrm{COU}$ was performed through a calibration curve.

An FLX solution was prepared from a stock solution with concentrations of 5.0, 10.0, 15.0, 45.0 and $75.0 \mathrm{mg} \mathrm{L}^{-1}$ to implement the photolytic assay. All solutions were prepared from analytical grade chemicals and ultra-pure water with a minimum of $18.0 \mathrm{M} \Omega \mathrm{cm}$ resistivity obtained in a Milli-Q Plus system (Millipore, Bedford, MA, USA). The standards/solutions were stored in high-density polypropylene bottles (Nalgene ${ }^{\circledast}$, New York, USA) and were kept refrigerated.

\section{UV and UV/MW reactors (spectral regions)}

To determine the spectral emission bands of the different reactors, the spectroradiometer was introduced into the UV reactor chamber (Figure 1a) and spectral data were collected. It is important to note that the spectroradiometer remained at the same time as the irradiated samples remained from the source of irradiation.

For the UV/MW reactor, the Hg-MDEL was placed on top of the equipment, and the spectroradiometer was positioned in front of the upper opening of the lamp (Figure 1b), thus allowing the spectral data collection. It is important to note that the radiometric measurement in this system was performed under these conditions due to the incompatibility of inserting the spectroradiometer in the microwave, but for the purposes of this study, the data are sufficient for comparison and previous understanding of the different reactors.

\section{Formation of hydroxyl radicals}

To study the formation of hydroxyl radicals in different reactors (UV/MW and UV), standard solutions of $\mathrm{COU}$ were prepared at concentrations of 0.1 to $100 \mathrm{mg} \mathrm{L}^{-1}$ and their absorbances were determined at different concentrations by molecular absorption spectrophotometry (COU $335 \mathrm{~nm}$ ). $10 \mathrm{~mL}$ of $50 \mathrm{mg} \mathrm{L}^{-1} \mathrm{COU}$ were then subjected to radiation in the time of 3 to $300 \mathrm{~min}$ (UV reactor) and 0.083 to $2 \mathrm{~min}$ (UV/MW reactor), and the COU was quantified. In order to obtain more consistent data, the influence of the addition of the hydroxyl radical scavenger was evaluated and $100 \mu \mathrm{L}$ of DMSO was added to $10 \mathrm{~mL}$ of the $50 \mathrm{mg} \mathrm{L}^{-1} \mathrm{COU}$ solution.

\section{Effect of the microwave power study}

The power study was performed on a CEM MARS 6 to evaluate the influence of microwave radiation on the UV/MW degradation process of FLX. For the conduction of these studies, $10 \mathrm{~mL}$ of $10 \mathrm{mg} \mathrm{L}^{-1}$ FLX was transferred to UV/MW reactor with a sample compartment of $10 \mathrm{~mL}$ of quartz and supported in a $250 \mathrm{~mL}$ glass beaker. The FLX solutions were subjected to $30 \mathrm{~s}$ fixed-period degradation assay, varying the microwave power in the range of 10 to $1,800 \mathrm{~W}$.

\section{Effect of the $\mathrm{pH}$}

A $20 \mathrm{mg} \mathrm{L}^{-1}$ FLX solution was prepared and the $\mathrm{pH}$ was adjusted with a $0.1 \mathrm{~mol} \mathrm{~L}^{-1}$ solution of $\mathrm{NaOH}$ or $\mathrm{HCl}$. For $\mathrm{pH}$ monitoring, a glass membrane electrode, coupled to a digital potentiometer (LUCA 210) was used. Solutions with $\mathrm{pH}$ values $2,5,7,9$ and 11 were prepared, which were added to the UV reactor and irradiated for a period of up to $60 \mathrm{~min}$. The solutions were added to the UV/MW reactor, irradiated for up to $2 \mathrm{~min}$ and then monitored by molecular absorption spectrophotometry at $225 \mathrm{~nm}$.

\section{Effect of the initial concentration of FLX}

In this study, $10 \mathrm{~mL}$ of FLX solution at concentrations of 5.0 to $75.0 \mathrm{mg} \mathrm{L}^{-1}(\mathrm{pH}=6.51)$ were transferred to a $50 \mathrm{~mL}$ glass beaker and added to a UV reactor for irradiation (constant stirring). The solutions were irradiated 
in the time interval of 3 to $100 \mathrm{~min}$. An aliquot $(30 \mu \mathrm{L})$ of the solutions was subjected to chemical analysis by HPLC, for quantification of FLX and its respective TPs. Also in this step, another aliquot $(5 \mathrm{~mL})$ was used for quantification of fluoride through the potentiometry with a fluoride ion selective electrode. In this analysis, the ionic strength of the solution was adjusted with an acetate buffer.

In order to compare the efficiency of the UV/MW reactor with the UV reactor, the optimum degradation parameters for the UV system were defined and subsequently applied to the UV/MW reactor (sample volume of $10 \mathrm{~mL}, \mathrm{pH}_{\mathrm{O}}=6.51$, and $\mathrm{FLX}_{\mathrm{O}}=10 \mathrm{mg} \mathrm{L}^{-1}$ ).

\section{Effect of the application of different reactors}

An aliquot $(10 \mathrm{~mL})$ of FLX solution $\left(10 \mathrm{mg} \mathrm{L}^{-1}\right)$ was transferred to a $50 \mathrm{~mL}$ glass beaker and inserted into the UV reactor, remaining exposed to radiation under constant stirring. For the assay using UV/MW reactor, $10 \mathrm{~mL}$ of the FLX solutions were transferred to the reactor, which was supported in a $250 \mathrm{~mL}$ glass beaker (Figure $1 \mathrm{~b}$ ) assay. The microwave power applied at this stage was $200 \mathrm{~W}$. After assay of degradation in time intervals of 3 to $120 \mathrm{~min}$ (UV) and 0.083 to $5 \mathrm{~min}$ (MW and UV/MW), the solutions were analyzed by HPLC and potentiometry with a fluoride ion selective electrode. The limitation of $5 \mathrm{~min}$ of irradiation to the UV/MW and MW reactor occurs due to the observation of the temperature elevation in the system, therefore, avoiding the loss of the solution and the maintenance of the temperature in the process.

\section{Results and Discussion}

\section{UV and UV/MW reactors (spectral regions)}

The results of the spectral emission for the different reactors are shown in Figure 2, verifying the presence of seven

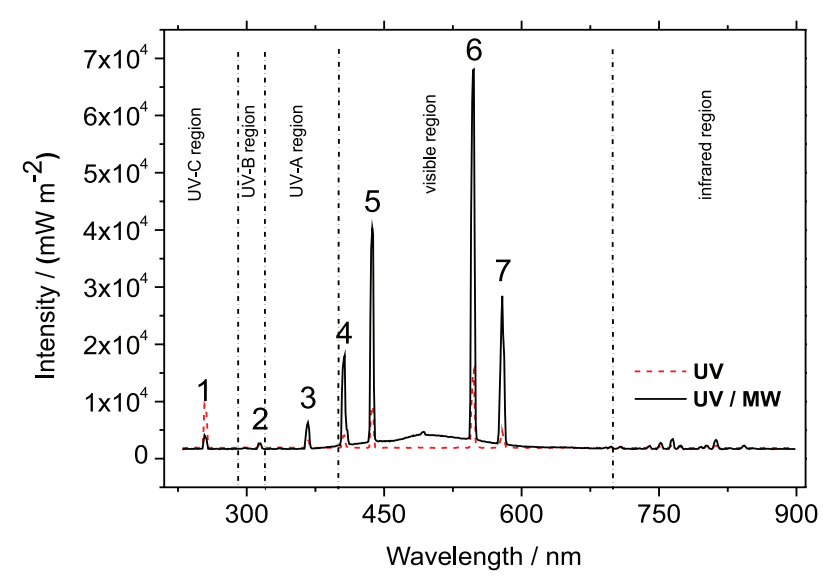

Figure 2. Spectral emission lines for UV and UV/MW photoreactors determined by spectroradiometer.

main emission regions. The spectral bands were identical for both systems starting in the UV region C (254 nm), passing through the UV regions B (314 nm), UV-A $(367 \mathrm{~nm})$ and visible regions (406 to $579 \mathrm{~nm}$ ).

In addition to verifying the difference between the intensities in Figure 2, Table 1 presents a comparison between the different regions and their respective intensities.

The UV system has a single spectral region $(254 \mathrm{~nm})$ with a higher intensity than the UV/MW system. For all other regions, the UV/MW reactor has an intensity far superior to the UV reactor, especially for the visible regions, where the intensity values are $300 \%$ higher than in the UV reactor, reaching almost $500 \%$ in the region of $579 \mathrm{~nm}$.

In the case of the UV/MW reactor, we are obviously dealing with a reactor where high intensities are reached $\left(10^{3}\right.$ for the region of $367 \mathrm{~nm}$ and $10^{4}$ for the region close to $400 \mathrm{~nm}$ ), when compared to values in the literature $\left(10^{1}\right)$ for the region of $367 \mathrm{~nm}$ and near the region of $400 \mathrm{~nm} .{ }^{18}$

It is important to note that UV/MW reactor have a spectral region characterized by the emission of

Table 1. The emission spectra of UV and UV/MW reactors and the radiation intensity for different wavelengths, as well as comparative spectral intensity values

\begin{tabular}{|c|c|c|c|c|}
\hline \multirow{2}{*}{ Peak $^{\mathrm{a}}$} & \multirow{2}{*}{ Wavelength / nm } & \multicolumn{2}{|c|}{ Intensity / (W m²) } & \multirow{2}{*}{$\begin{array}{l}\text { Increase of intensity when comparing the } \\
\text { UV/MW reactor to the UV reactor / \% }\end{array}$} \\
\hline & & UV/MW reactor & UV reactor & \\
\hline 1 & 254 & 4.0 & 9.4 & -58 \\
\hline 2 & 314 & 2.8 & 2.4 & 18 \\
\hline 3 & 367 & 6.3 & 3.4 & 87 \\
\hline 4 & 406 & 17.9 & 4.1 & 334 \\
\hline 5 & 437 & 40.2 & 9.1 & 343 \\
\hline 6 & 547 & 68.1 & 15.6 & 337 \\
\hline 7 & 579 & 28.4 & 4.8 & 494 \\
\hline
\end{tabular}

aThis identification is related to Figure 2. UV: ultraviolet; MW: microwave. 
wavelengths of 185, 254, 297, 313, 365, 405, 436, 546, $577,579 \mathrm{~nm} .{ }^{29}$ As found in the Figure 2, the same spectra can be observed, with the exception of the $185 \mathrm{~nm}$, which cannot be determined due to the spectroradiometer limit $(230-900 \mathrm{~nm})$ used in this work. Therefore, emission of the spectrum in the $185 \mathrm{~nm}$ region cannot be ruled out, and the confirmation of hydroxyl radicals in the system is associated with water photolysis, which occurs for wavelengths $<190 \mathrm{~nm}^{35}$

\section{Formation of hydroxyl radicals}

COU is a photochemically stable compound under UV radiation, ${ }^{36}$ but when in the presence of hydroxyl radicals, it is rapidly oxidized to its hydroxylated forms ${ }^{37}$ Being widely applied in studies of the identification of hydroxyl radicals in photochemical systems, this was applied to identify hydroxyl radicals in the present study. ${ }^{20,38,39}$

Figure 3 a shows the variation of the $\mathrm{COU}$ concentration during the irradiation in the UV and UV/MW reactors, revealing that for the UV reactor the formation of hydroxyl radicals is not confirmed since the COU decay is not verified for the irradiation interval of up to $300 \mathrm{~min}$. For the UV reactor, an increase in COU concentration is verified with the course of the irradiation time. This behavior is justified by the fact that the UV reactor remains open for time intervals of up to $300 \mathrm{~min}$, which leads to the loss of water, and consequently increasing the $\mathrm{COU}$ concentration.

In the UV/MW reactor, the decay of COU occurs throughout irradiation time, suggesting that the photolysis of the water and the consequent formation of hydroxyl radicals can be proposed as an oxidation mechanism of
COU. For better proof of hydroxyl radical formation, the DMSO (hydroxyl radical scavenger) ${ }^{40-42}$ was added in the UV/MW reactor, inhibiting the oxidation of COU, as shown in Figure 3a. The DMSO was chosen for being widely used as a hydroxyl radical scavenger in photochemical studies and for not interfering in the COU quantification process. The concentration of COU increases from $45 \mathrm{~min}$, reaching maximum value after $300 \mathrm{~min}$ of irradiation. In this case, the increase in concentration is justified, once the reactor is opened and the water loss occurs due to the balance between the liquid/gas phases. For the UV/MW reactor, this increase in concentration is not considerable, since the irradiation time is of maximum $2 \mathrm{~min}$.

The hydroxylation of COU by hydroxyl radicals is reported in the literature ${ }^{36,37}$ and the COU conversion rates in 7-hydroxycoumarin were determined up to $7.0 \%,{ }^{20}$ confirming the formation of the hydroxylated products. For the present study, the hydroxylation kinetics of $\mathrm{COU}$ were determined at $0.178 \mathrm{~min}^{-1}\left(\mathrm{R}^{2}=0.998\right)$, as shown in Figure $3 \mathrm{~b}$. Since the light emission in the UV/MW reactor is very high (for all spectral regions) and the incidence rate at the solution is $100 \%$, the photolysis of the water is effective for the formation of the hydroxyl radicals.

\section{Effect of the microwave power}

The study of microwave power evidenced a high degradation of FLX through the UV/MW reactor, and after $30 \mathrm{~s}$ of irradiation, FLX removal was above $95 \%$ for an applied power of $200 \mathrm{~W}$. Above $200 \mathrm{~W}$ of power the removal rate did not have a very significant positive variation. It reached the removal value of $99 \%$ in the power
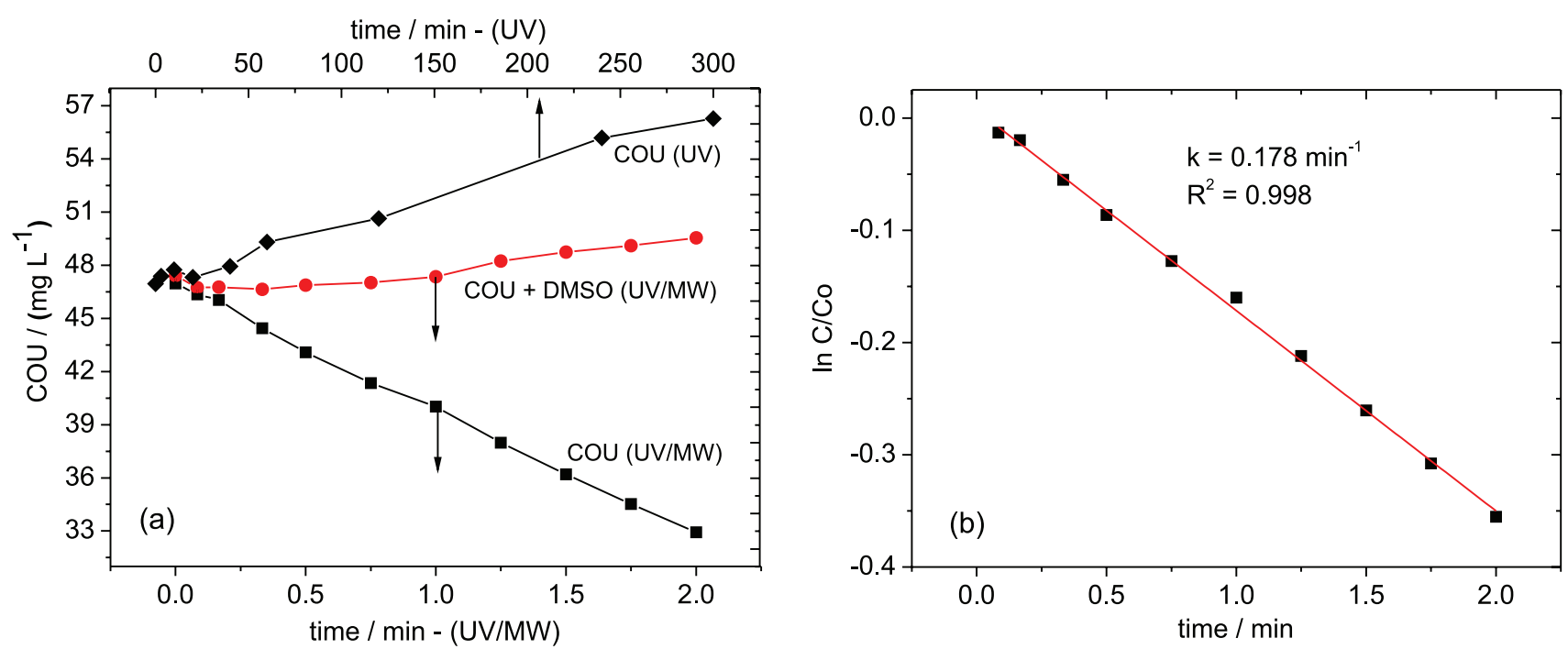

Figure 3. (a) COU concentration variation after UV/MW and UV photodegradation in system added with DMSO; (b) COU kinetics behavior in the UV/MW system. 

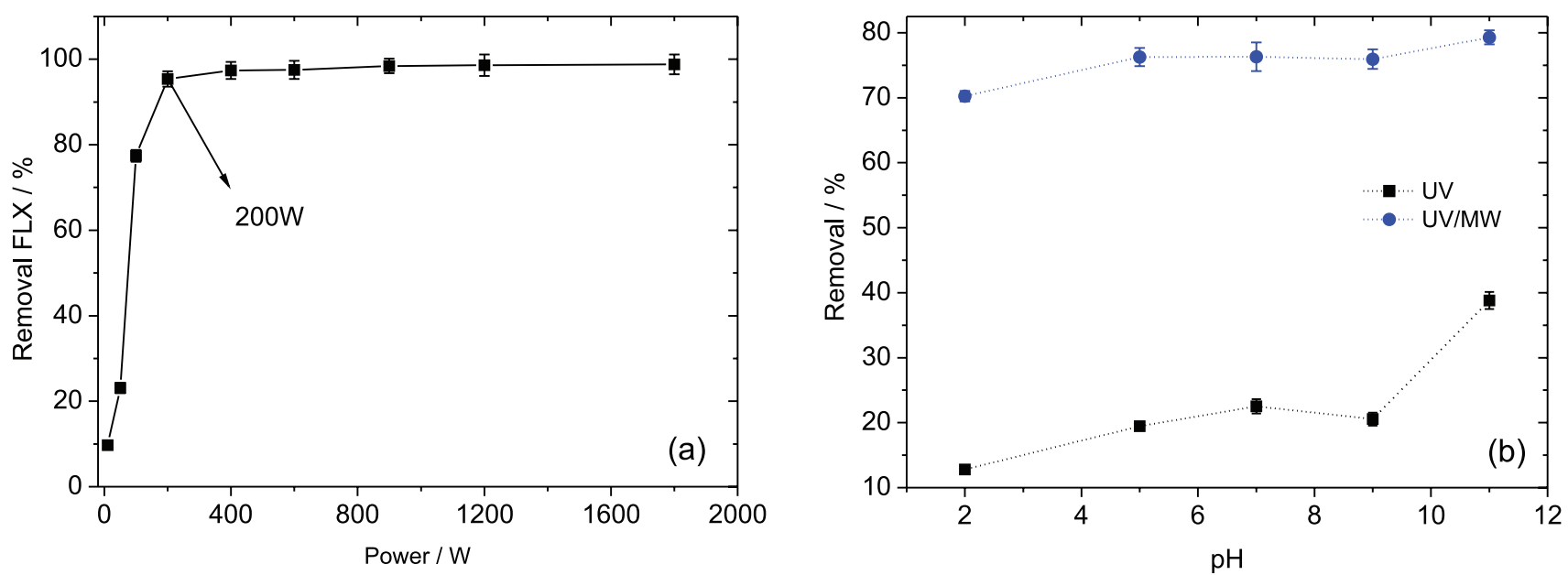

Figure 4. (a) Influence of microwave power on the removal of $10 \mathrm{mg} \mathrm{L}^{-1} \mathrm{FLX}$ solution during a period of $30 \mathrm{~s}$ of UV/MW irradiation; (b) influence of the $\mathrm{pH}$ on the degradation process of the irradiated $20 \mathrm{mg} \mathrm{L}^{-1} \mathrm{FLX}$ solution during a period of 60 min with UV radiation.

range of 400 to $1800 \mathrm{~W}$, as can be seen in Figure 4a. The respective step is important for the purpose of quantifying process costs since energy consumption is closely linked to the applied power and the time of use of the equipment. The observation that the increase of power above $200 \mathrm{~W}$ does not exert a significant increase in the rate of degradation of FLX permits limited use of power.

From equation 1, it is calculated the energy consumption for each unit of concentration $\left(\mathrm{mg} \mathrm{L}^{-1}\right)$ of degraded FLX. Considering that $95 \%$ of FLX $\left(10 \mathrm{mg} \mathrm{L}^{-1}\right)$ is degraded by $200 \mathrm{~W}$, it is not justifiable using power above $200 \mathrm{~W}$.

Energy Consumption $\left(\frac{\mathrm{kW} \mathrm{h}}{\mathrm{mg} \mathrm{L}^{-1}}\right)=\frac{\mathrm{Pt}}{\mathrm{C}_{0}-\mathrm{C}_{\mathrm{t}}}$

where $\mathrm{P}$ is the power $(\mathrm{kW} \mathrm{h}), \mathrm{t}$ is the time of reaction (h), $\mathrm{C}_{0}$ is the initial concentration of FLX, while $\mathrm{C}_{\mathrm{t}}$ is its concentration after $t$ hours of reaction.

According to the data obtained and the respective rates of FLX removal, all subsequent tests applying the UV/MW reactor were conducted by applying a microwave power of $200 \mathrm{~W}$.

Using the UV/MW reactor in $200 \mathrm{~W}$, an FLX degradation of $95 \%$ was achieved in $0.5 \mathrm{~min}$. On the other hand, for the UV reactor (4 UV bulbs, $15 \mathrm{~W}$ each), FLX degradation of $99 \%$ was achieved in 120 min. By applying this data in equation 2 , we have the energy consumption of $1.94 \times 10^{-4} \mathrm{~kW} \mathrm{~h} \mathrm{mg}^{-1} \mathrm{~L}$ for the first case, and $1.2 \times 10^{-2} \mathrm{~kW} \mathrm{~h} \mathrm{mg}^{-1} \mathrm{~L}$ in the last case. This is a difference of approximately two decimal units in energy consumption, showing that for the degradation of FLX, the UV/MW reactor has an energy efficiency that is extremely superior to the UV reactor. The energy consumption in $\mathrm{kW} \mathrm{h} \mathrm{kg}{ }^{-1}$ is reported in the literature, ${ }^{12,13}$ and in this work, the $\mathrm{kW} \mathrm{h} \mathrm{mg}^{-1} \mathrm{~L}$ ratio was used.
Effect of $\mathrm{pH}$

The $\mathrm{pH}$ studies using UV reactor show that, for the values evaluated (2.0, 5.0, 7.0, 9.0 and 11.0), the most significant variation in the degradation of FLX occurs at $\mathrm{pH}=11$, and for the lower values, the variation is not relevant. According to Figure 4b, the removal rate of FLX was $39 \%$ for $\mathrm{pH}=11$ versus $13 \%$ for $\mathrm{pH}=2$ and removal rates close to $20 \%$ for the other $\mathrm{pH}$ values. The higher degradation of FLX at basic $\mathrm{pH}$ is in agreement with the results obtained in the literature. ${ }^{5,43}$ At these $\mathrm{pH}$ values, the amount of neutral molecules is higher, resulting in an increase in the rate degradation. At $\mathrm{pH}=11$, the FLX $\left(\mathrm{p} K_{\mathrm{a}}=10.4\right)$ undergoes deprotonation, and according to Yin et al. ${ }^{17}$ under different $\mathrm{pH}$ conditions, the drug has different light absorption rates, which influence its photolytic degradation rate.

For UV/MW reactor, the highest degradation of FLX can be attributed to the highest amount of hydroxyl radicals formed during the probable photolysis of the water. In the UV reactor, FLX photolysis is favored in basic media, according to the literature ${ }^{15}$ and for UV photolysis, FLX deprotonation at $\mathrm{pH} \geq 11$ influences light absorption. ${ }^{17}$ However, for UV/MW reactor the $\mathrm{pH}$ variation for the degradation process is not significant (Figure $4 b$ ), showing that the radical oxidation has a greater influence on the process than the photolysis.

Although degradation of FLX at $\mathrm{pH}=11$ was $16 \%$ higher than at $\mathrm{pH}=7$ (the second highest rate of degradation with a value of $23 \%$ ), the high degradation in the UV/MW reactor in short time intervals allows to establish values close to $\mathrm{pH}=7$ for future work, since the steps of $\mathrm{pH}$ adjustment and reagent expense would be eliminated. Thus, the FLX degradation studies were performed at values close to $\mathrm{pH}=7$. 


\section{Effect of the initial concentration of FLX}

Studies corresponding to the influence of the initial concentration of FLX showed a significant decrease in FLX already in the first 20 min of exposure to UV radiation (Figure 5a). TFMP formation in the first $20 \mathrm{~min}$ was observed (Figure 5b), indicating that the degradation of FLX results in the formation of its trihalogenated TPs. Consequently showing that in this period, dehalogenation is not the main mechanism of FLX degradation. However, the dehalogenation is also verified from the first instants of irradiation, presenting a slightly linear variation throughout the study period (Figure 5c). Furthermore, the data is compatible with the literature, ${ }^{16}$ which observes a formation of approximately $2.28 \mathrm{mg} \mathrm{L}^{-1}$ of fluoride after $2 \mathrm{~h}$ of irradiation of $35 \mathrm{mg} \mathrm{L}^{-1} \mathrm{FLX}$, and the present study verified $2.2 \mathrm{mg} \mathrm{L}^{-1}$ of fluoride formation for experimental conditions (45 $\mathrm{mg} \mathrm{L}^{-1} \mathrm{FLX}, 1 \mathrm{~h}$, without catalyst), evidencing the tendency of dehalogenation.

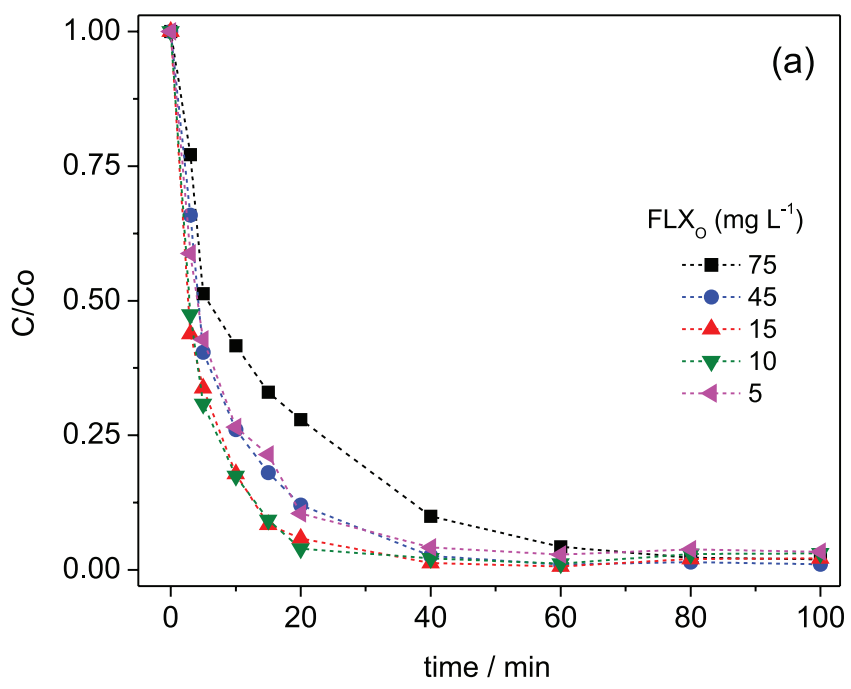

The degradation of FLX results in the formation of TFMP, which according to Figure 6, when submitted to the different processes, generates TFMP and fluoride products (quantified in this study), and qualitatively (TFMP) and quantitatively (fluoride) reported by Salazar et al. ${ }^{6}$

The kinetics of the reaction can be simplified by the set of equations presented below.

$-\frac{\mathrm{dC}}{\mathrm{dt}}=\mathrm{kCI}_{\mathrm{UV}}$

where $\mathrm{k}$ is the rate constant, $\mathrm{C}$ is the concentration of the FLX and $\mathrm{I}_{\mathrm{UV}}$ is the luminous intensity.

Since the reaction was performed in water under a constant illumination rate, the term $\mathrm{I}_{\mathrm{UV}}$ can be inserted in $\mathrm{k}$, as follows:

$-\frac{\mathrm{dC}}{\mathrm{dt}}=\mathrm{k}^{\prime} \mathrm{C} ;$ where $\mathrm{k}^{\prime}=\mathrm{kI}_{\mathrm{UV}}$

Stating the initial concentration as $\mathrm{C}_{0}$, and the final

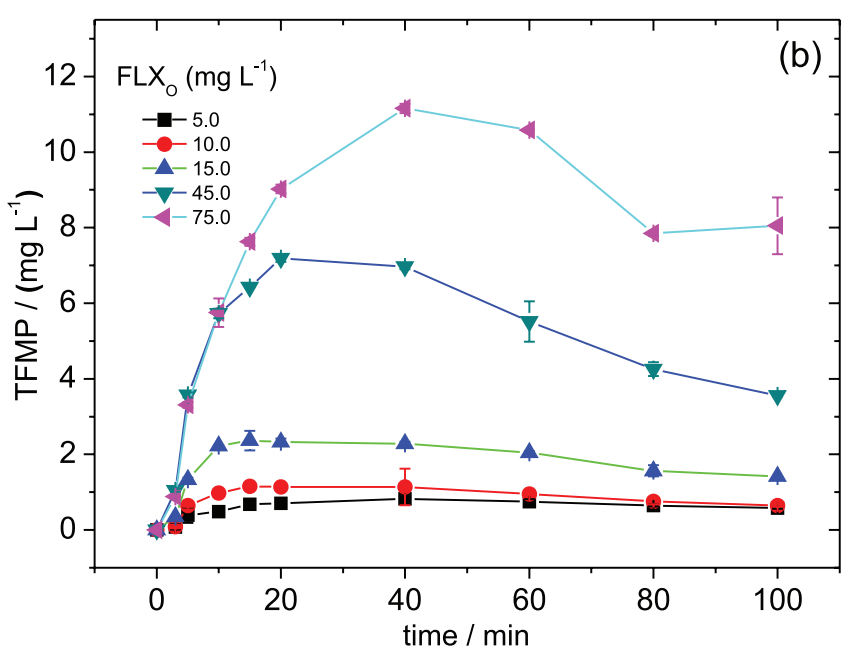

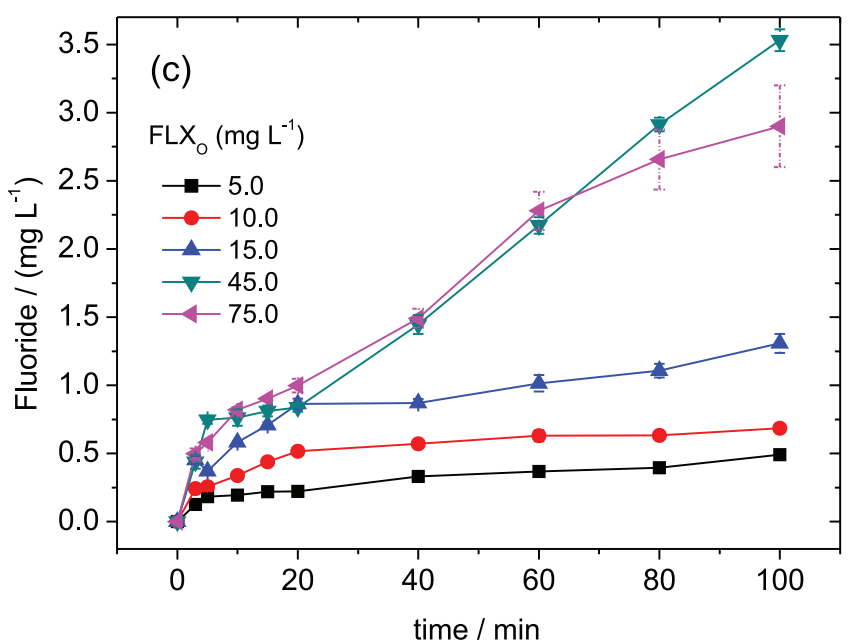

Figure 5. (a) Effect of the initial concentration on the FLX degradation process; (b) formation of TFMP; (c) formation of fluoride using UV reactor. 


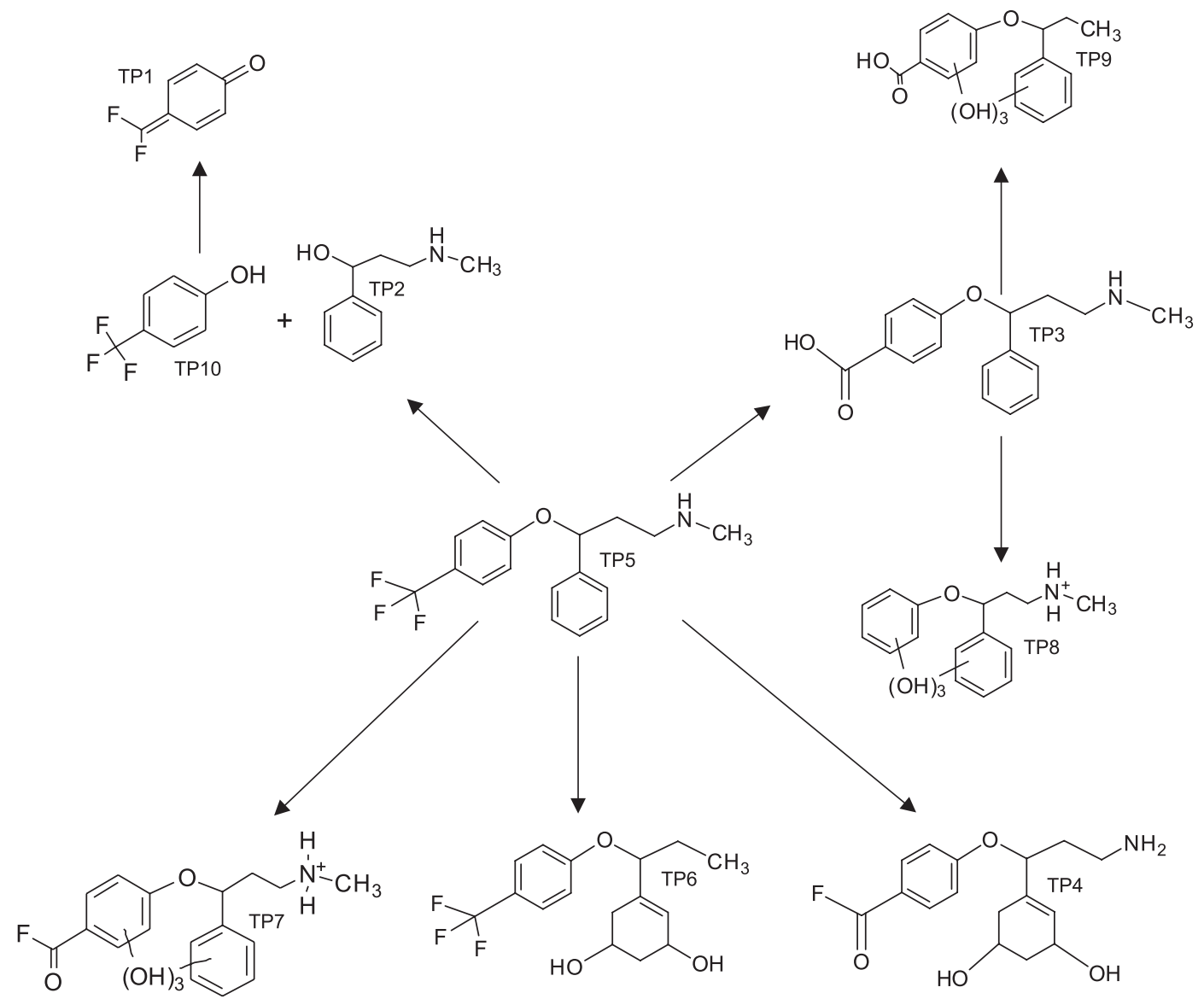

Figure 6. The proposed FLX degradation mechanism after UV and UV/MW photodegradation, and monitoring by LC-MS/Q-TOF.

concentration as $\mathrm{C}$, and integrating, we obtain the following equation and the plots shown in Figure 7 for all samples.

$\ln \left(\frac{\mathrm{C}}{\mathrm{C}_{0}}\right)=\mathrm{k}^{\prime} \mathrm{t}$

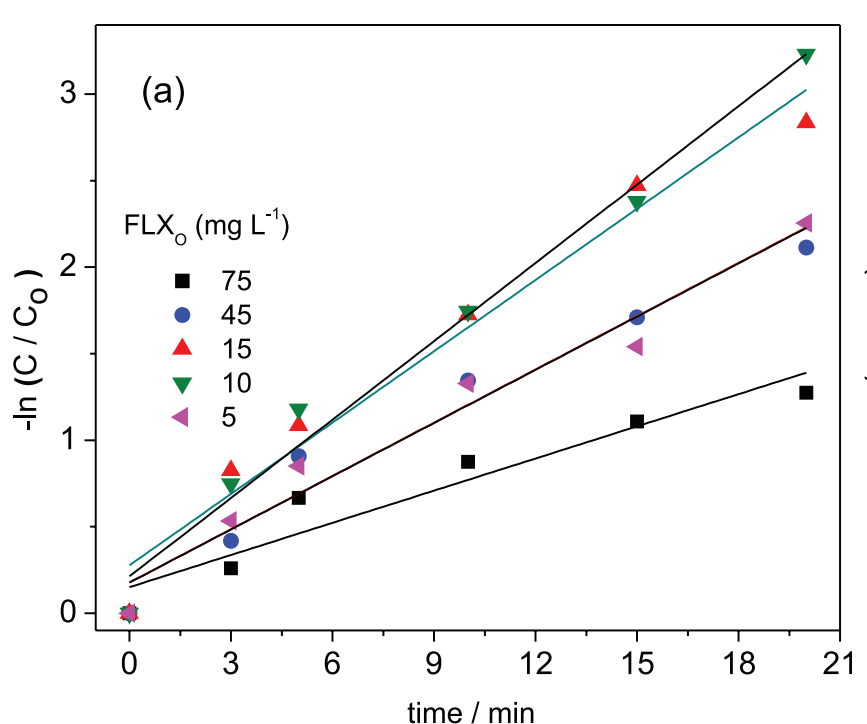

Figure $7 \mathrm{a}$ was obtained by plotting the data until 20 min of reaction, while the kinetics was influenced by the TPs formed during UV radiation. Table 2 shows the $\mathrm{k}$ ' values obtained by the slope in the graph presented in Figure 7a.

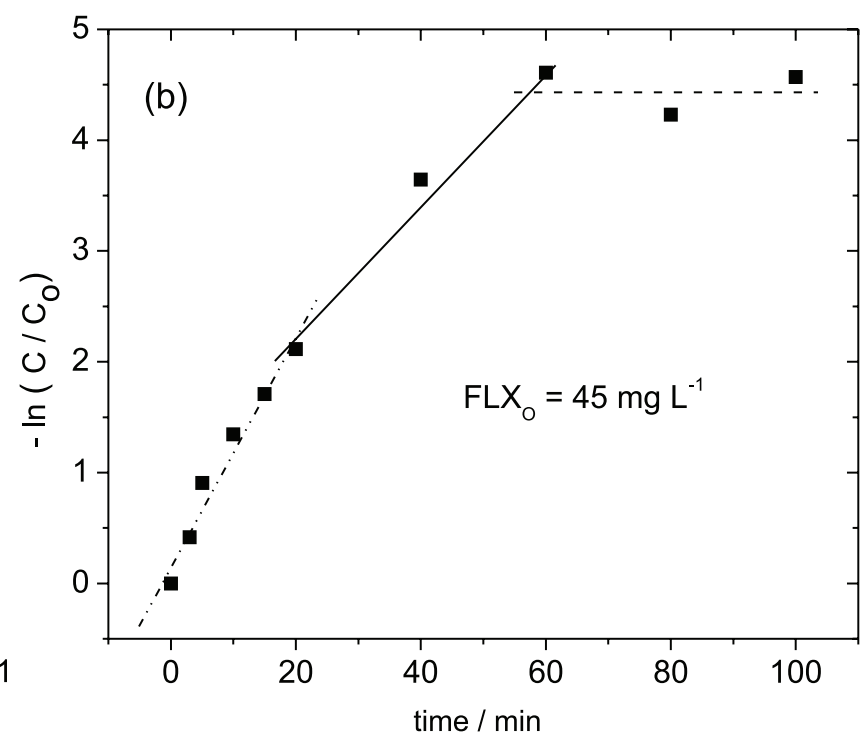

Figure 7. (a) Lines of linear regression obtained for FLX degradation data up to $20 \mathrm{~min}$; (b) kinetic behavior for the time interval up to 100 min. 
Considering the first-order kinetics with respect to FLX, we can obtain the values of the rate constant k', which are presented in Table 2.

Table 2. Constant pseudo-first-order kinetics as a function of the initial concentration of FLX

\begin{tabular}{lcc}
\hline $\begin{array}{l}\text { Initial concentration } \\
\text { of FLX } /\left(\mathrm{mg} \mathrm{L}^{-1}\right)\end{array}$ & $\mathrm{k}^{\prime} \times 10^{-3} / \mathrm{min}^{-1}$ & $\mathrm{R}^{2}$ \\
\hline 75 & 61 & 0.900 \\
45 & 102 & 0.954 \\
15 & 137 & 0.963 \\
10 & 150 & 0.980 \\
5 & 102 & 0.958 \\
\hline
\end{tabular}

FLX: fluoxetine; $k^{\prime}$ : constant pseudo-first-order kinetics; $\mathrm{R}^{2}$ : linear correlation coefficient.

The TFMP molecules are not the unique TPs formed by UV photolysis. ${ }^{19}$ Therefore, the rate of FLX degradation and TFMP formation are not the same. However, by analyzing the data in the first three minutes of reaction, it can be detected that around 5\% of degraded FLX were converted to TFMP. As it can be seen in Figure 5b, the amount of TFMP during UV irradiation for different FLX initial concentrations presents an initial increase and a further decrease with the continuous illumination because they are also degraded by the UV photolytic process. As a consequence, an important point regarding the FLX degradation kinetics is that since TFMP and other TPs are also absorbent of photons and the value of $\mathrm{I}_{\mathrm{UV}}$ is constant, the value of $\mathrm{k}^{\prime}$ in equation 4 is proportional to $\mathrm{I}_{\mathrm{UV}}$. In fact, Figure $7 \mathrm{~b}$ shows the entire batch of $\ln \left(\mathrm{C} / \mathrm{C}_{0}\right)$ for the initial concentration of $45 \mathrm{mg} \mathrm{L}^{-1}$. As a result, the values of k' were obtained for the first $20 \mathrm{~min}$, being minimum the influence of the TPs under the kinetic degradation of the FLX.

It is noteworthy that the kinetic constant results presented in this study are in agreement with the literature, ${ }^{8}$ that present pseudo-first-order kinetics constant for the FLX degradation with values in the range $0.170-0.370 \mathrm{~min}^{-1}$ for a degradation time of up to $20 \mathrm{~min}$.

For the present study, considering the degradation time (20 min), the values of the constant can be verified in Table 2. The study of the initial concentration allows evaluating that not only the concentration of FLX influences the kinetics of the reaction, but also their TPs. Different values of kinetic constant were obtained in studies conducted by Salazar et al., ${ }^{6}$ when different initial concentration of FLX was applied. The results are justified by the authors, due to parasitic reactions that occur during the degradation of FLX. The TPs, when formed in greater quantity, begin to compete with the FLX in the degradation process, and thus, the value of $\mathrm{k}$ is influenced. ${ }^{6}$ Thus, knowing the greater amount of TPs formed during the degradation of FLX is necessary, and the reactivity of these TPs needs to be better evaluated during the FLX degradation process. Moreover, the formation of fluoride ions at the beginning of the process indicates probable dehalogenation of TFMP, indicating likely competition of FLX and TFMP in the degradation stage. Considering that the first order kinetics has been applied in studies with FLX, this work addresses its application to the different reactors (UV and UV/MW), evaluating the respective degradation results for FLX.

\section{Effect of the application of different reactors}

The efficiency of the UV/MW reactor for the degradation of FLX is highlighted when compared to degradation reactor using UV and MW. During the degradation of FLX, the formation of TFMP and the release of fluoride ions show a rupture of the ether bond of the compound and other dehalogenation mechanisms (Figure 6). The mechanism of degradation by radical attack has been reported in the literature ${ }^{16}$ suggesting that photolysis of water allows the formation of highly reactive hydroxyl radicals. In the present study, the formation of hydroxyl radicals was confirmed for the UV/MW reactor by COU.

According to the mechanism proposed in Figure 6, in addition to the formation of TFMP (formed by direct photolysis and by radical oxidation), TP1 may represent 4-(difluoromethylidene) cyclohexa-2,5-dien-1-one and TP2, the $\alpha$-[2-(methylamino)ethyl]benzyl alcohol. ${ }^{10,15,19}$ Table 3 shows the results of FLX degradation when different energies are applied during irradiation and the

Table 3. Results of FLX degradation by the different reactors, and formed concentration of the TFMP and fluoride

\begin{tabular}{lcccc}
\hline Reactor & Irradiation time / min & FLX degradation $/ \%$ & TFMP formation $/\left(\mathrm{mg} \mathrm{L}^{-1}\right)$ & Fluoride formation $/\left(\mathrm{mg} \mathrm{L}^{-1}\right)$ \\
\hline MW & 5 & 29.01 & $<\mathrm{LOD}^{\mathrm{a}}$ & $<\mathrm{LOD}^{\mathrm{b}}$ \\
UV & 120 & 98.90 & 0.69 & 1.06 \\
UV/MW & 5 & 99.16 & $<\mathrm{LOD}^{\mathrm{a}}$ & 1.08 \\
\hline
\end{tabular}

a Limit of detection $\left(\right.$ TFMP) $=0.157 \mathrm{mg} \mathrm{L}^{-1}$; blimit of detection (fluoride) $=0.006 \mathrm{mg} \mathrm{L}^{-1}$. FLX: fluoxetine; TFMP: 4-(trifluoromethyl) phenol; UV: ultraviolet; MW: microwave. 
dehalogenation of FLX/TFMP can be correlated to the increase of the fluoride concentration in the UV and UV/MW reactors. The degradation processes by photolysis, hydrolysis, and biodegradation of FLX are presented in the literature, ${ }^{44}$ with degradation of up to $0.13 \%$ for hydrolysis and $0.52 \%$ for photolysis under the conditions of this experiment. Studies also report that FLX is stable against photolysis and hydrolysis (under the conditions of the experiment). ${ }^{18}$

The kinetic performance in oxidative processes performed by the oxidation of hydroxyl radicals is demonstrated in this work, where the application of first-order kinetics for the UV/MW reactor yields $\mathrm{k}=6.15 \pm 0.08 \mathrm{~min}^{-1}$ and $\mathrm{R}^{2}=0.998$. This is a value that represents an increase above $100 \%$ when compared to the UV reactor $\left(\mathrm{k}=0.15 \pm 0.01 \mathrm{~min}^{-1}, \mathrm{R}^{2}=0.980\right)$ under the same concentration conditions. The lower degradation by MW radiation shows that the isolated energy does not contribute to the formation of hydroxyl radicals,
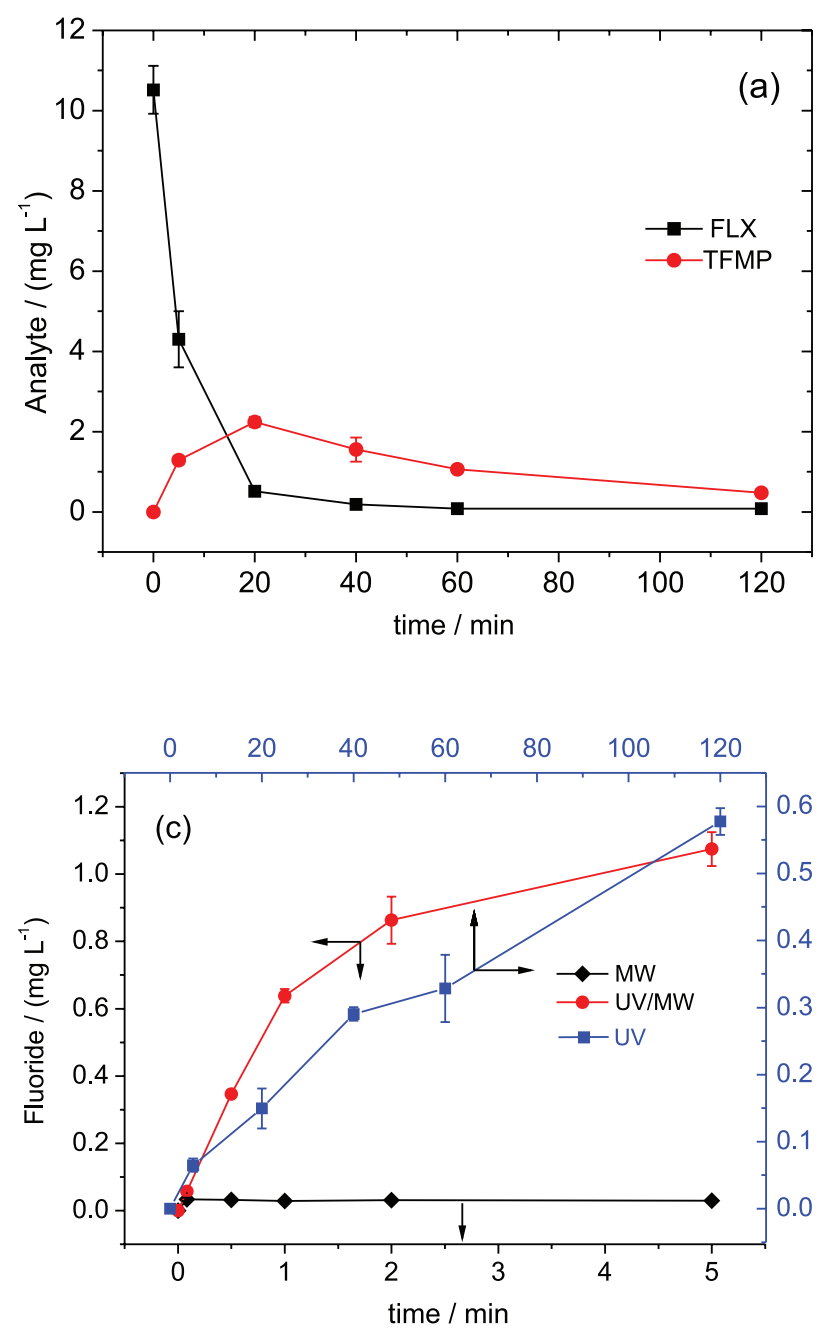

where the degradation occurs by hydrolysis. For the UV process, which has a degradation rate (99\% in $120 \mathrm{~min}$ ), the formation of hydroxyl radicals has not been proven, attributing the degradation of FLX to the UV photolytic process. For the UV/MW reactor, the degradation of the FLX presents a value of $99.2 \%$ in time of up to $5 \mathrm{~min}$, being accompanied by the evolution of fluoride and TFMP.

Figure 8 presents the FLX degradation data, the formation of TFMP and fluoride by applying different energies.

The higher efficiency of the UV/MW reactor is also confirmed by the fluoride evolution data (Figure 8c), where $46 \%$ higher concentration of fluoride is verified when compared to the UV reactor. This observation is important, since the evolution of fluoride is a consequence of the degradation processes of FLX and its halogenated TPs. Considering that FLX and TFMP are totally degraded in 2 min (Figures $8 \mathrm{a}$ and $8 \mathrm{~b}$ ) when the UV/MW reactor is applied, and that the evolution of fluoride proceeds in
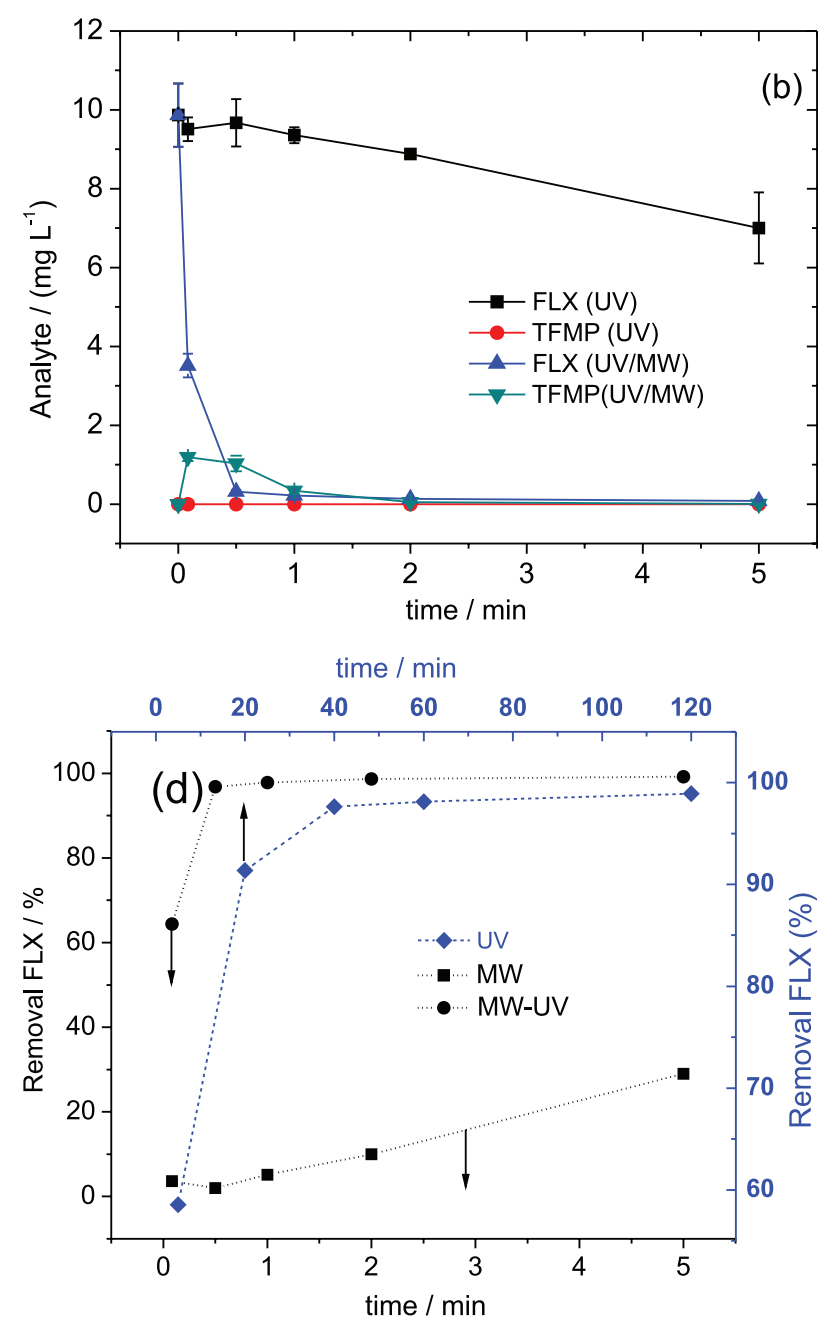

Figure 8. FLX degradation and TFMP formation were applied when the degradation processes (a) UV; (b) UV/MW; (c) fluoride formation and (d) percent rates of FLX removal were applied. 
periods above $2 \mathrm{~min}$, we can consider that this process of dehalogenation is attributed to the degradation of TPs that were formed during the FLX degradation process. In general, the UV/MW reactor has the potential to degrade FLX and its TPs in short time intervals.

It is noteworthy that many photochemical processes are applied in combination with peroxide,${ }^{45}$ iron, ${ }^{11}$ ozone and semiconductors, ${ }^{13}$ to increase efficiency. In this sense, the system used in this work presents high degradation efficiency without the insertion of other reagents/materials, which contributes to minimize costs. In addition to the costs involved with reagent/materials in the combined processes, there is the cost associated with the treatment of these materials, which can generate other wastes, such as ironcontaining sludge from the photo-Fenton process, costing US\$ 196 per tonne, according to Cheng et al. ${ }^{46}$ Finally, the tests in the laboratory scale (UV/MW process) search to contribute to the development of more robust systems, allowing the evaluation of the real costs, for higher volumes of treated effluent.

\section{Identification of intermediates by LC/MS-Q-TOF}

Table 4 shows the TPs detected by the high-resolution Q-TOF mass spectrometry, evidencing that due to the spectra $\left(\mathrm{m} / z\left[\mathrm{H}^{+}\right]\right)$, the hydrolysis, photolysis, and radical oxidation processes are established (as proposed in Experimental section). Since the COU assays have demonstrated that hydroxyl radical-mediated oxidation is not the main mechanism of degradation of FLX for the UV reactor, photolysis and direct hydrolysis are the most evident mechanisms. However, a contribution of the radical oxidation processes cannot be ruled out since, similar to observed in literature, ${ }^{47}$ the generation of hydroxyl radicals through UV photolysis of water is possible.

According to the results obtained and illustrated in Figures S1 and S2 (Supplementary Information (SI) section), the TPs presented in the FLX degradation mechanism are observed in both reactors (UV and UV/MW), and correspond to photolysis, hydrolysis and oxidation processes of FLX, as reported in the literature. ${ }^{10,16,19}$ The degradation of the FLX presents as main transformation product, TP4, the process being initiated by hydrolyzing the bond carbon and following the oxidation of the aromatic ring. These results are in agreement with the fluoride formation data in the reaction system, since TP4 is the result of the dehalogenation process, following the stoichiometry of 1:2 (FLX:fluoride).

When the UV / MW reactor was applied, the chromatographic signal of TP4 (Figure S3, SI section) in the first $0.083 \mathrm{~min}$, was equivalent to $75 \%$ of the signal verified for the UV reactor, when irradiated for $60 \mathrm{~min}$. These results are equivalent to 1.33 (UV) and $723 \% \mathrm{~min}^{-1}$ (UV/ MW), being related to the higher capacity that the UV/ MW reactor possesses in hydroxyl radical formation and to promote oxidation more efficiently, according to the steps proposed by equations 5 to 7 . It is important to report that after 2 min of irradiation, the signals observed for the TPs showed low intensity in the UV/MW reactor and the result of the degradation was more pronounced. However, as for the UV reactor, the observed signals for the TPs still showed significant signs after $60 \mathrm{~min}$, especially for TP3 and TP4.

$\mathrm{H}_{2} \mathrm{O}+\mathrm{hv} \rightarrow \mathrm{H}^{+}+\mathrm{e}_{\mathrm{aq}}^{-}+\mathrm{HO}^{\circ}$

$\mathrm{HO}^{\circ}+\mathrm{FLX} \rightarrow \mathrm{TFMP}+$ byproducts

$\mathrm{e}_{\mathrm{aq}}^{-}+$FLX $\rightarrow$ byproducts

After reporting a significant amount of TPs resulting from degradation of FLX by applying the reactors (UV and UV/MW), it can be concluded that its degradation kinetics may be influenced by these TPs, and therefore, the first order kinetics was applied in a limited time to $20 \mathrm{~min}$. The structures suggested in this work for FLX degradation TPs through the different processes are supported in the literature. ${ }^{10,19,48-50}$ The structures, mass spectra and degradation mechanisms are detailed in Figure 6 and Table 4.

Finally, Table 5 presents some comparative data of degradation of FLX, applying different degradation processes, including those discussed in this study (UV and UV/MW). The tabulated data (Table 5) show that for the different processes, FLX degrading rates are different. The TPs formed also vary for the different degradation processes, as well as identical TPs $\left(m / z\left[\mathrm{H}^{+}\right] 166,143\right.$, 326) are verified for different processes. In general, it is confirmed that different processes guide the degradation mechanisms of the FLX.

\section{Conclusions}

The application of the microwave assisted process (UV/MW reactor) presents very efficient results for the degradation of FLX (99.2\% in 5 min), while the UV process (98.9\% in $120 \mathrm{~min}$ ) presents less significant values (UV/MW is $95.8 \%$ more efficient than UV process in relation to the degradation time). The results concerning the low microwave energy consumption for the degradation of FLX further contribute to the applicability of the microwave assisted process in effluent treatment systems of the respective drug (the application of the UV/MW reactor will be the subject of further study in a later work). The kinetic discussion of the process is of great importance 
Table 4. Transformation products (TP) identified by LC-MS/Q-TOF for UV and UV/MW reactor

\begin{tabular}{|c|c|c|c|c|c|c|}
\hline $\begin{array}{l}\text { Transformation } \\
\text { product }\end{array}$ & $t_{R} / \min$ & $m / z\left[\mathrm{H}^{+}\right]$ & $\begin{array}{c}\text { Elemental } \\
\text { composition }\end{array}$ & $\begin{array}{c}\text { Calculated } \\
\text { mass }\end{array}$ & Error / ppm & Molecular structure (suggestion) \\
\hline TP1 & 0.26 & 143.0039 & $\mathrm{C}_{7} \mathrm{H}_{4} \mathrm{~F}_{2} \mathrm{O}$ & 142.0229 & a & \\
\hline TP2 & 0.52 & 166.1176 & $\mathrm{C}_{10} \mathrm{H}_{15} \mathrm{NO}$ & 165.1176 & -13.64 & \\
\hline TP3 & 2.55 & 286.1454 & $\mathrm{C}_{17} \mathrm{H}_{19} \mathrm{NO}_{3}$ & 285.1381 & -1.64 & \\
\hline TP4 & 4.74 & 310.1428 & $\mathrm{C}_{16} \mathrm{H}_{20} \mathrm{FNO}_{4}$ & 309.1356 & 6.73 & \\
\hline TP5 & 5.33 & 310.1426 & $\mathrm{C}_{17} \mathrm{H}_{18} \mathrm{~F}_{3} \mathrm{NO}_{4}$ & 309.1354 & -4.27 & \\
\hline TP6 & 6.32 & 317.1382 & $\mathrm{C}_{16} \mathrm{H}_{19} \mathrm{~F}_{3} \mathrm{O}_{3}$ & 316.1300 & -4.33 & \\
\hline TP7 & 6.88 & 337.2361 & $\mathrm{C}_{17} \mathrm{H}_{20} \mathrm{FNO}_{5}$ & 336.2283 & a & \\
\hline TP8 & 7.33 & 291.2545 & $\mathrm{C}_{16} \mathrm{H}_{20} \mathrm{NO}_{4}$ & 290.3337 & a & \\
\hline TP9 & 8.11 & 305.2732 & $\mathrm{C}_{16} \mathrm{H}_{16} \mathrm{O}_{6}$ & 304.2652 & a & \\
\hline $\mathrm{TP} 10^{\mathrm{b}}$ & - & $161.0221(\operatorname{ESI}(-))$ & $\mathrm{C}_{7} \mathrm{H}_{5} \mathrm{~F}_{3} \mathrm{O}$ & 162.0293 & -0.54 & \\
\hline
\end{tabular}

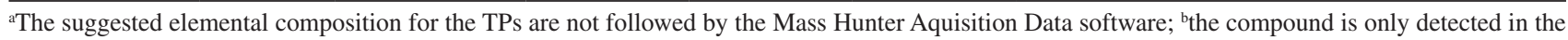
ESI(-) mode, and thus, its retention time is not being reported. $t_{\mathrm{R}}$ : retention time; $m / z$ : mass spectrum. 
Table 5. Comparative data of removal of FLX and formation of TPs, when applied different degradation processes

\begin{tabular}{|c|c|c|c|c|}
\hline Degradation process & $\begin{array}{l}\text { Initial concentration } \\
\text { of FLX / }\left(\mathrm{mg} \mathrm{L}^{-1}\right)\end{array}$ & Removal; time / \%; min & $\begin{array}{l}\text { Mass spectra identified } \\
\left(\mathrm{m} / z\left[\mathrm{H}^{+}\right]\right)\end{array}$ & Reference \\
\hline Electrochemical degradation & 20 & $97 ; 10$ & $\begin{array}{l}163.0390 / 166.1228 / \\
326.1365 / 358.1254\end{array}$ & Wang et al..$^{51}$ \\
\hline Electron beam irradiation & 19 & $90 ; 0.5 \mathrm{KGy}^{\mathrm{a}}$ & $\begin{array}{c}143.0090 / 166.1315 / \\
182.1273 / 198.1233 / \\
326.1547 / 342.1507 / \\
358.1467 / 376.1583 / \\
392.1543\end{array}$ & Silva et al..$^{10}$ \\
\hline Hybrid catalytic/ozonation & 34 & $100 ; 10$ & $\begin{array}{c}32 / 104 / 129 \text { / } 166 / 326 / \\
342 / 358 / 374 / 390 / \\
416 / 432\end{array}$ & Arriaga et al..$^{15}$ \\
\hline Electron beam irradiation & 50 & $100 ; 2 \mathrm{KGy}^{\mathrm{a}}$ & $163 / 166 / 288 / 326$ & Shao et al. ${ }^{50}$ \\
\hline UV photolysis ${ }^{\mathrm{b}}$ & 10 & $98 ; 120^{\mathrm{b}}$ & $\begin{array}{l}143.0039 / 166.1176 / \\
286.1454 / 310.1428 / \\
310.1426 / 317.1382 /\end{array}$ & present study ${ }^{\mathrm{b}}$ \\
\hline UV/MW photolysis ${ }^{\mathrm{b}}$ & 10 & $99 ; 5^{\mathrm{b}}$ & $\begin{array}{c}337.2361 / 291.2545 / \\
305.2732 /(161.0221 \mathrm{ESI}(-))\end{array}$ & \\
\hline
\end{tabular}

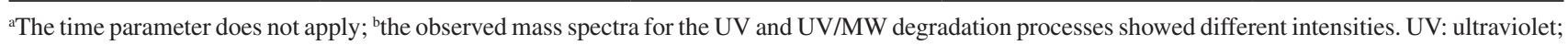
UV/MW: ultraviolet/microwave; FLX: fluoxetine; ESI(-): negative electrospray; TPs: transformation products; $m / z$ : mass spectrum.

for the understanding of the degradation mechanisms because the values of the FLX degradation constants pose a kinetic behavior dependent on the applied time interval, and the results obtained in the present study show that it is not possible to conclude on the true degradation kinetics of FLX without considering the TPs formed. Finally, the formation of TFMP results from the degradation of FLX and the probable dehalogenation of TFMP occurs soon after, which is proven by the formation of fluoride alongside the systems. It should also be noted that the values of the kinetic constant (order 1) obtained from the photolytic degradation of FLX must be performed within the time interval, in which the degradation of TFMP is not evident. When degradation of TFMP occurs concomitantly with degradation of FLX, interference in the degradation mechanism is proven, resulting in kinetic constants that can not be adjusted to order 1 .

\section{Supplementary Information}

Supplementary information (chromatograms and mass spectra of the identified TPs after degradation process of FLX) are available free of charge at http://jbcs.sbq.org.br as PDF file.

\section{Acknowledgments}

The authors would like to thank the Fundação de Amparo à Pesquisa do Estado de Minas Gerais (FAPEMIG) for the financial support (process number: APQ-02823-14) and Coordenação de Aperfeiçoamento de Pessoal de Nível Superior (CAPES). V. R. M. would like to thank CNPq for the financial support under the project CNPq/SETEC 468956/2014-0.

\section{References}

1. Grabicova, K.; Grabic, R.; Blaha, M.; Kumar, V.; Cerveny, D.; Fedorova, G.; Randak, T.; Water Res. 2015, 72, 145.

2. Kostich, M. S.; Batt, A. L.; Lazorchack, J. M.; Environ. Pollut. 2014, 184, 354.

3. Péry, A. R. R.; Gust, M.; Vollat, B.; Mons, R.; Ramil, M.; Fink, G.; Ternes, T.; Garric, J.; Chemosphere 2008, 73, 300.

4. Ambuludi, S. L.; Panizza, M.; Oturan, N.; Oturan, M. A.; Catal. Today 2014, 224, 29.

5. Galvis, E. A. S.; Agredo, J. S.; Aguirre, A. L. G.; Palma, R. A. T.; Sci. Total Environ. 2015, 524-525, 354.

6. Salazar, C.; Ridruejo, C.; Brillas, E.; Yáñez, J.; Mansilla, H. D.; Sirés, I.; Appl. Catal., B 2017, 203, 189.

7. Horikoshi, S.; Abe, M.; Serpone, N.; Photochem. Photobiol. Sci. 2009, 8, 1087.

8. Hu, A.; Zhang, X.; Luong, D.; Oakes, K. D.; Servos, M. R.; Liang, R.; Kurdi, R.; Peng, P.; Zhou, Y.; Waste Biomass Valorization 2012, 3, 443.

9. Meybodi, A. A.; Ebadi, A.; Shafiei, S.; Khataee, A. R.; Rostampour, M.; J. Taiwan Inst. Chem. Eng. 2015, 48, 40.

10. Silva, V. H. O.; Batista, A. P. S.; Teixeira, A. C. S.; Borrely, S. I.; Environ. Sci. Pollut. Res. 2016, 23, 11927.

11. Perini, J. A. L.; Silva, B. C.; Tonetti, A. L.; Nogueira, R. F. P.; Environ. Sci. Pollut. Res. 2017, 24, 6233. 
12. Wang, H.; Bakheet, B.; Yuan, S.; Li, X.; Yu, G.; Murayama, S.; Wang, Y.; J. Hazard. Mater. 2015, 294, 90.

13. Mudliar, R.; Umare, S. S.; Ramteke, D. S.; Wate, S. R.; J. Hazard. Mater. 2009, 164, 1474.

14. Brázon, E. M.; Piccirillo, C.; Moreira, I. S.; Castro, P. M. L.; J. Environ. Manage. 2016, 182, 486.

15. Arriaga, M. F.; Otsu, T.; Oyama, T.; Gimenes, J.; Esplugas, S.; Hidaka, H.; Serpone, N.; Water Res. 2011, 45, 2782.

16. Hidaka, H.; Tsukamoto, T.; Oyama, T.; Mitsutsuka, Y.; Takamura, T.; Serpone, N.; Photochem. Photobiol. Sci. 2013, 12,751 .

17. Yin, L.; Ma, R.; Wang, B.; Yuan, H.; Yu, G.; RSC Adv. 2017, 7, 8280.

18. Kwon, J. W.; Armbrust, K. L.; Environ. Toxicol. Chem. 2006, $25,2561$.

19. Lam, M. W.; Young, C. J.; Mabury, S. A.; Environ. Sci. Technol. 2005, 39, 513.

20. Nagarajan, S.; Skillen, N. C.; Fina, F.; Zhang, G.; Randon, C.; Lawton, L. A.; Irvine, J. T. S.; Robertson, P. K. J.; J. Photochem. Photobiol., A 2017, 334, 13.

21. Liu, Z. Q.; Tan, Z. R.; Wang, D.; Huang, S. L.; Wang, L. S.; Zhou, H. H.; J. Chromatogr. B: Anal. Technol. Biomed. Life Sci. 2002, 769, 305.

22. El-dawy, M. A.; Mabrouk, M. M.; El-barbary, F. A.; J. Pharm. Biomed. Anal. 2002, 30, 561.

23. Alves, V.; Gonçalves, J.; Conceição, C.; Teixeira, H. M.; Câmara, J. S.; J. Chromatogr. A 2015, 1408, 30.

24. Ribeiro, A. R.; Maia, A. S.; Moreira, I. S.; Afonso, C. M.; Castro, P. M. L.; Tiritan, M. E.; Chemosphere 2014, 95, 589.

25. Hu, E.; Cheng, H.; Water Res. 2014, 57, 8.

26. Xu, L. J.; Chu, W.; Graham, N.; J. Hazard. Mater. 2014, 275 , 166.

27. Moreira, A. J.; Borges, A. C.; Gouveia, L. F. C.; Macleod, T. C. O.; Freschi, G. P. G.; J. Photochem. Photobiol., A 2017, 347, 160.

28. Ta, N.; Hong, J.; Liu, T.; Sun, C.; J. Hazard. Mater. 2016, 138, 187.

29. Církva, V.; Relich, S.; Curr. Org. Chem. 2011, 15, 248.

30. Církva, V.; Hájek, M.; J. Photochem. Photobiol., A 1999, 123 , 21.
31. Nüchter, M.; Ondrusschka, B.; Jungnickel, A.; Müller, U.; J. Phys. Org. Chem. 2000, 13, 579.

32. Klán, P.; Literák, J.; Relich, S.; J. Photochem. Photobiol., A 2001, 143, 49.

33. Moreira, A. J.; Pinheiro, B. S.; Araújo, A. F.; Freschi, G. P. G.; Environ. Sci. Pollut. Res. 2016, 23, 18502.

34. Zhang, X.; Sun, D. D.; Li, G.; Wang, Y.; J. Photochem. Photobiol., A 2008, 199, 311.

35. Zoschke, K.; Börnick, H.; Worch, E.; Water Res. 2014, 52, 131.

36. Czili, H.; Horváth, A.; Appl. Catal., B 2008, 81, 295.

37. Louit, G.; Foley, S.; Cabillic, J.; Coffigny, H.; Taran, F.; Valleix, A.; Renault, J. P.; Pin, S.; Radiat. Phys. Chem. 2005, 72, 119.

38. Ishibashi, K.; Fujishima, A.; Watanabe, T.; Hashimoto, K.; Electrochem. Commun. 2000, 2, 207.

39. Lin, Z. R.; Zhao, L.; Dong, Y. H.; Chemosphere 2015, 141, 7.

40. Treml, J.; Smejkal, K.; Compr. Rev. Food Sci. Food Saf. 2016, 15,720 .

41. Wiegand, H. L.; Orths, C. T.; Kerpen, K.; Lutze, H. V.; Schmidt, T. C.; Environ. Sci. Technol. 2017, 51, 14321.

42. Lee, C.; Yoon, J.; Chemosphere 2004, 57, 1449.

43. Do, T. T. T.; Dao, U. P. N.; Bui, H. T.; Nguyen, T. T.; Chem. Phys. Lipids 2017, 207, 10.

44. Styrishave, B.; Sørensen, B. H.; Ingerslev, F.; Environ. Toxicol. Chem. 2011, 30, 254.

45. Salazar, C. S.; Satuf, M. L.; Alfano, O. M.; Cassano, A. E.; Environ. Sci. Technol. 2008, 42, 6198.

46. Cheng, Y.; Chen, Y.; Lu, J.; Nie, J.; Liu, Y.; Environ. Sci. Pollut. Res. 2018, 25, 12083.

47. Line, M. R.; Vasish, G.; Chen, P.; Angerhausen, D.; Yung, Y. L.; Astrophys. J. 2011, 32, 738.

48. Szabó, L.; Mile, V.; Kiss, D. J.; Kovács, K.; Földes, T.; Németh, T.; Tóth, T.; Homlok, R.; Balogh, G. T.; Takács, E.; Wojnárovits, L.; Chemosphere 2018, 193, 489.

49. Shao, H. Y.; Wu, M. H.; Deng, F.; Xu, G.; Liu, N.; Li, X.; Tang, L.; Chemosphere 2018, 190, 184.

50. Wang, C.; Niu, J.; Yin, L.; Huang, J.; Hou, L. A; Chem. Eng. J. 2018, 346, 662 .

Submitted: October 7, 2018 Published onlline: December 19, 2018 